\title{
Achieving standardised reporting of suicide in Australia: rationale and program for change
}

Diego De Leo, Michael J Dudley, Caroline J Aebersold, John A Mendoza, Michael A Barnes, James E Harrison and David L Ranson

S uicide and intentional self-harm are issues of major importance in public health, public interest and public policy. In Australia, suicide rates are widely used as a progress indicator in these areas. ${ }^{1}$ Accurate suicide statistics underpin appropriately targeted suicide prevention strategies and research, costing of suicide and combating associated stigma. Reliable statistical information on suicide is thus vital.

The first release, in 2009, of Australian Bureau of Statistics (ABS) cause-of-death data registered in 2007 recorded 1884 suicides, about $75 \%$ of which involved males. ${ }^{2}$ Suicide accounted for $19 \%$ of deaths among 15-34-year-old males, while men aged 85 years or older had the highest rates of suicide. Suicides significantly exceed the number of fatalities from motor vehicle accidents and homicides. Non-fatal suicidal behaviour (self-harm) is a leading cause of morbidity, especially for young women. There are no Australian estimates of the substantial human, social and economic costs of suicide and self-harm. In California in the United States, they approximate $\$ 4.2$ billion per year. ${ }^{3}$ Each suicide affects at least six other people. ${ }^{3}$

Suicide rates in Australia, especially in younger people, increased during the later 20th century, peaking in 1997. Reasons advanced for the subsequent decline include the rising economic

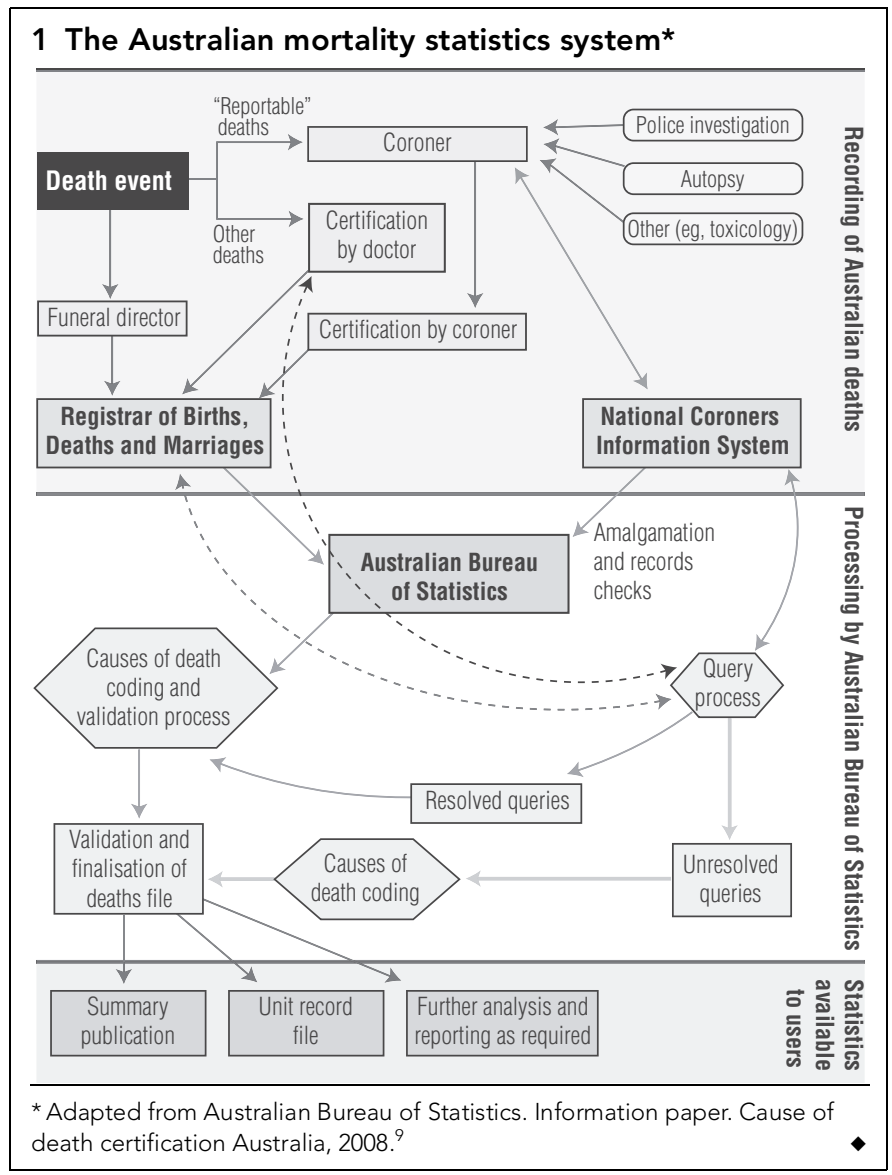

\section{ABSTRACT}

- Suicide and intentional self-harm are issues of major importance in public health and public policy, with rates widely used as progress indicators in these areas.

- Accurate statistics are vital for appropriately targeted prevention strategies and research, costing of suicide and to combat associated stigma.

- Underreporting of Australian suicide rates probably grew from 2002 to 2006; Australian Bureau of Statistics (ABS) suicide data were at least $11 \%$ or $16 \%$ undercounted (depending on case definitions) in 2004.

- In coronial cases with undetermined intent for 2005 to 2007, intentional self-harm was found in 39\%.

- Systemic reasons for undercounting include: (i) absence of a central authority for producing mortality data; (ii) inconsistent coronial processes for determining intent, as a result of inadequate information inputs, suicide stigma, and high standards of proof; (iii) collection and coding methods that are problematic for data stakeholders; and (iv) lack of systemic resourcing, training and shared expertise.

- Revision of data after coronial case closure, beginning with ABS deaths registered in 2007, is planned and will reduce undercounting.

- Other reasons for undercounting, such as missing or ambiguous information (eg, single-vehicle road crashes, drowning), differential ascertainment (eg, between jurisdictions), or lack of recorded information on groups such as Indigenous people and gay, lesbian, bisexual and transgender people require separate responses.

- A systemic coordinated program should address current inaccuracies, and social stigma about suicide and self-harm must be tackled if widespread underreporting is to stop.

MJA 2010; 192: 452-456

For editorial comment, see page 428. See also page 432

prosperity in the 1990s, ${ }^{4}$ an increase in prescriptions for antidepressants that modify psychiatric risk factors, ${ }^{5}$ governmentfunded suicide prevention strategies, ${ }^{6-8}$ and underreporting.

Here we describe underreporting, especially from 2002 to 2007, examine its reasons, and suggest remedial strategies.

\section{Determination and reporting of suicides in Australia}

Legal, statistical and research data on suicide are currently discrepant, yet a single set of official data is desirable. Locating where any suicide is coded in the pathway to Australian Bureau of Statistics (ABS) output data, is challenging (Box 1).

No single body or portfolio is responsible for producing mortality data, and several systemic factors contribute to suicide under- 


\begin{tabular}{|c|c|c|c|}
\hline \multicolumn{4}{|c|}{$\begin{array}{l}2 \text { Deaths registered in Australia of people aged } 10 \text { years } \\
\text { or older from intentional self-harm or unintentional } \\
\text { injury by hanging or firearm, }{ }^{*} 1997-2006\end{array}$} \\
\hline \multirow[b]{2}{*}{ Year } & \multirow{2}{*}{$\begin{array}{l}\text { Deaths caused by } \\
\text { intentional self-harm }\end{array}$} & \multicolumn{2}{|c|}{ Unintentional deaths } \\
\hline & & Asphyxia & Firearm \\
\hline 1997 & 2720 & 140 & 19 \\
\hline 1998 & 2683 & 201 & 22 \\
\hline 1999 & 2492 & 182 & 28 \\
\hline 2000 & 2362 & 184 & 44 \\
\hline 2001 & 2454 & 181 & 18 \\
\hline 2002 & 2320 & 199 & 31 \\
\hline 2003 & 2213 & 245 & 39 \\
\hline 2004 & 2098 & 324 & 54 \\
\hline 2005 & 2101 & 242 & 50 \\
\hline 2006 & 1799 & 386 & 56 \\
\hline \multicolumn{4}{|c|}{$\begin{array}{l}\text { *Underlying cause coded according to the International Classification of } \\
\text { Diseases, 10th revision, with code ranges including: intentional self-harm, } \\
\text { X60-X84; asphyxia, W75-W80; and firearms, W32-W34. Data obtained from } \\
\text { the National Injury Surveillance Unit, based on Australian Bureau of Statistics } \\
\text { cause-of-death data. }\end{array}$} \\
\hline
\end{tabular}

reporting. Different parties are involved in death investigation, certification and data collection: police, state and territory registries, forensic medical and scientific staff, coroners, the National Coroners Information System (NCIS), the ABS and, sometimes, funeral directors (who identify the deceased, which is a vital role in identifying Indigenous deaths: Box 1). Each party collects and records different information for different purposes (legal, statistical, research), with potentially different standards of proof and different problems with reporting deaths. A central component is coronial non-determination of intent, about which individual coroners are often cautious, ${ }^{8}$ and even legally constrained (eg, South Australia; see below); nationally, 29\% of coroners omit reference to intent (Jessica Pearse, Manager, NCIS, personal communication). Yet, even if coroners always determined intent, systemic and legislative constraints would remain. Lack of information to coroners, data stakeholders' collection and coding methods, and resourcing, training and collective shared expertise, are all significant factors in the quality of mortality data.

\section{Evidence of underreporting and corrective measures}

Suicide underreporting occurs internationally, ${ }^{10}$ and in some regions, this undermines useable information. Moreover, no suicide data are available for more than half of the world's countries, most of which are developing countries in Asia, Africa and South America. ${ }^{11-13}$

In Australia, ABS-coded suicide deaths have fallen by a third since 1997. However, "accidental" deaths by common suicide methods (hanging and shooting) have risen, particularly after 2002 (Box 2). In 2004, ABS coders classified 81 intentional selfharm deaths as "Other accidental threats to breathing" (International Classification of Diseases, 10th revision [ICD-10] codes, W75-W84). ${ }^{1}$ The Queensland Suicide Register (QSR) noted that 73 hanging suicides in Qld in 2006 had been coded as accidental.

Of 12786 cases recorded on the NCIS as deaths by intentional self-harm between mid-2000 and the end of 2005, the ABS

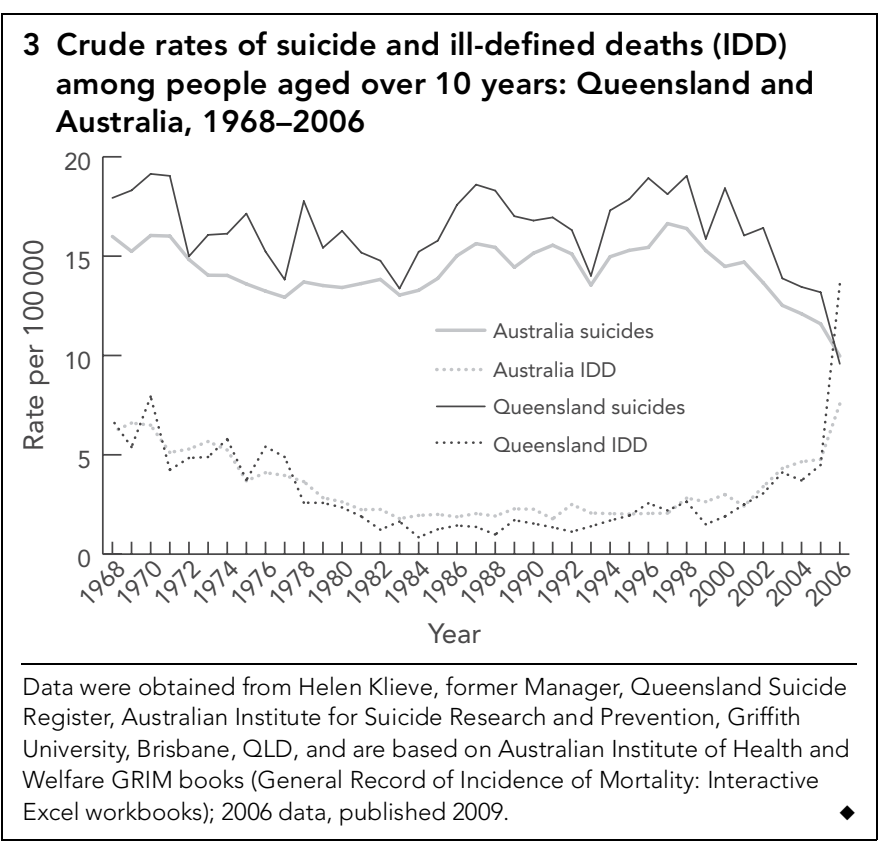

ascribed non-suicide ICD-10 cause-of-death codes to at least 8.9\% of these. ${ }^{14}$ Suicides in 2004 were underreported by $11 \%$ or $16 \%$, depending on case definitions. ${ }^{1}$ The level of underreporting was probably higher, because some coroner cases remained open at the time of study in early 2008. ${ }^{1}$

It may be thought that coroners' findings determine suicide coding. A random, cross-jurisdictional sample of 988 NCIS cases involving external causes of death from 2005 to 2007 found that, of 284 cases where coroners made no reference to intent (29\%), the NCIS judged 111 (39\%) as involving intentional self-harm. Methods strongly indicative of suicide — hanging, motor vehicle exhaust and plastic bag asphyxia - were used in 86 of these (77\%) (Jessica Pearse, Manager, NCIS, personal communication). Thus, coroners' findings regarding intent alone do not reliably indicate the prevalence of suicide.

The QSR contains about 10000 suicide cases from 1990, each with police, pathology, toxicology and (from 1994) psychological autopsy reports. QSR data to 2001 closely paralleled ABS data (within 5\%). However, the discrepancy has increased markedly since then, with 51 QSR suicide cases unreported by the ABS in 2002 ( 537 v 588; 8.7\%), 84 in 2003 (466 v 550; 15.3\%), 127 in 2004 (453 v 580; 21.9\%), 112 in 2005 (459 v 571; 19.6\%) and 187 cases in 2006 (340 v 527; 35.5\%). Data for 2007 (not yet finalised) confirm similar discrepancies.

Box 3 shows recent falling suicide rates coinciding with rising rates of ill-defined deaths, with similar patterns for Qld and Australia. ABS practices during 2002 to 2006 regarding ill-defined deaths require investigation, although only some ill-defined deaths may be due to misclassified suicide deaths. ${ }^{1}$

An analysis of deaths in $2004^{1}$ found the higher corrected estimate was 2458 suicide deaths, compared with 2110 in ABS 2004 data. As noted, some coroner cases from 2004 that were still open early in 2008 may be suicide deaths. Similar analyses for other years are unavailable, but a less elaborate analysis suggests a similar extent of misclassification in 2003, and somewhat less in 2001 and 2002. ${ }^{14}$ For 2006, conservative estimates would add at least 200 cases of suicide from New South Wales to Qld's 187 extra 
cases, as NSW apparently has similar problems with underreporting, ${ }^{1}$ and these two states contain about half of Australia's population. Adding other jurisdictions would add 650-700 suicide deaths to the 1799 reported by the ABS.

The misclassifications just noted principally depend on mismatching between some closures of coroner cases (with intentional self-harm confirmation) and the ABS's annual deadline for processing cases. ${ }^{1}$ To solve this problem, the ABS will revise data beginning with all deaths registered in 2007, though delayed caseclosure will prevent final counts for several years.

This undercounting undermines the validity of the apparently sharply declining suicide rates reported by the ABS for 2002-2006 (although declines may still have occurred from the peak year of 1997). Pending the release of final ABS data for 2007 and later years, and the findings of any further special studies of earlier years, rates of about 20 per 100000 (male population) for males and 5 per 100000 for females (female population) appear more plausible.

Suicide can also be undercounted because the available evidence leaves the cause of death uncertain. For example, some singlevehicle road crashes are suicide-related. ${ }^{15}$ Deaths in single-vehicle crashes rose from $38.4 \%$ of all vehicle-related deaths in the combined years 1999 and 2000 to $46.1 \%$ in the combined years 2006 and 2007:16 however, without positive evidence (eg, a suicide note), investigators cannot determine whether the cause was suicide or other factors. Similar uncertainty arises with some other deaths, such as drowning.

Ascertainment of suicide may also differ between groups. Differences between jurisdictions in closing coroner cases probably result in different levels of suicide misclassification. ${ }^{1}$ Use of less indicative methods by females compared with males (eg, overdose as opposed to hanging) may conceal female suicides. Small rural communities may report fewer suicides because of concerns about stigma and confidentiality. These possibilities require confirmation.

Different to undercounting, but contributing to ignorance about suicide risk factors and distribution, is a lack of information in death records on some characteristics of people dying by suicide. For example, evidence shows that Indigenous Australians aged 12-24 years have suicide rates four times greater than non-Indigenous Australians, ${ }^{17}$ but underidentification of Indigenous status at death hampers measurement and analysis. This varies by jurisdiction Western Australia, SA, Northern Territory and Qld are more reliable — but undercounting of probable Indigenous suicide is at least 25\% in NSW. ${ }^{18}$ Gay, lesbian, bisexual and transgender status is also seldom recorded at death despite over-representation of these groups among cases of suicide and self-harm. ${ }^{19,20}$

\section{Investigation of deaths, the coroner's role and determination of intent}

Each Australian state and territory has a coronial jurisdiction. Coroners are usually magistrates who investigate all reportable deaths, which should include all suspected suicides (although how completely this occurs is unknown). Coroners must establish the time, place, manner and cause of death and the deceased's identity.

Police, forensic pathologists and toxicologists investigate reportable deaths. For coroners and bodies that record death data to determine suicide, detailed, consistent information about circumstances and risk factors is required. To minimise local variations, several jurisdictions (Australian Capital Territory, Qld, Tasmania, NT and, recently [April 2009], NSW) have introduced (to varying degrees) a standard national police form that records evidence of suspected suicide and demographic data such as Aboriginality. As a result, data collection from suspected suicide cases in these jurisdictions has improved both in consistency over time and compared with other jurisdictions. ${ }^{2}$

Coroners may rule on intent, but Coroners Acts do not explicitly mandate this. Without an inquest, the SA Coroners Act only permits a finding as to cause, not circumstances, of death. Apart from those few suicides (excepting custodial deaths) that are subject to inquests, the state and deputy state coroners consider they are forbidden from finding on intent. Clerks independently complete this field (Mark Johns, State Coroner, South Australia Coroner's Office, personal communication). However, other Australian statutes oblige coroners to determine "how" the person died (Qld, Vic, Tas, WA), the "manner and cause of death" (NSW, ACT), and "any relevant circumstances concerning death" (NT). The coronial duty to investigate the (at least immediate) circumstances of death is imported into Australian legal judgments from common law, where coroners must seek and record as many facts as public interest requires. ${ }^{21-23}$ Though no one has an interest in challenging coronial omission of intent, it is arguable that the coroner should find on intent where possible.

Evidence for suicide may not suffice in drug overdoses, drownings, single-vehicle accidents and some other methods. Intentional self-harm may not equate to suicide if the person's capacity to form suicidal intent is doubtful, for example, because of youth, mental illness or cognitive impairment. ${ }^{2,8}$ In Australia, the gravity and consequences of a suicide finding require a civil standard of proof, but with a high degree of certainty. ${ }^{8}$ Consequent unavoidable subjectivity makes for inconsistency in findings.

Terminology (eg, in explicitly referring to suicide) and formatting vary greatly across jurisdictions, ${ }^{1}$ and among coroners, who may refer to intent or "let the facts speak for themselves" (eg, in cases of hanging or jumping in front of a train). ${ }^{8}$

Stigma associated with suicide (and suicide attempts ${ }^{24}$ ) has profound psychological and behavioural effects on individuals and families — who may avoid seeking help, and may conceal or deny suicide $^{25}$ — and also affects coronial practice. ${ }^{1,2,8,18}$ Considerations may include victims' ages (especially children and young people), social standing, families' or communities' distress and emotional wellbeing, cultural and religious interests, financial impact (insurance claims), and legislation. ${ }^{2}$ For example, the Qld Births, Deaths and Marriages Registration Act 2003 prohibits "suicide" being entered onto the register. Although anti-stigma campaigns flourish in mental health, ${ }^{26}$ destigmatising self-harm and suicide is controversial. Inappropriate media reportage of individual suicides may increase suicide rates, and concerns have also been expressed about public discussion normalising suicide. Concerns about effects such as these must be balanced against the costs of silence about a major social problem. Silence risks perpetuating underreporting and misinformation about suicide, ${ }^{27}$ and marginalising its victims.

\section{Data collection and reporting bodies}

The NCIS is the database of all deaths reported to Australian coroners since July 2000 (for Qld, since January 2001). Before the NCIS and until 2005, records with insufficient information prompted the ABS to have its staff visit coroners' offices to assign a cause of death. The query process, involving about 25000 deaths annually, continued until the ABS finished its annual compilation. Thereafter, the data file remained unaltered for incomplete coron- 


\section{Parties attending or consulted about the inaugural meetings of the National Committee for Standardised Reporting of Suicide in April and September 2009}

- Suicide Prevention Australia

- Australian Institute for Suicide Research and Prevention

- The Australian Bureau of Statistics

- National Coroners Information System

- Australian Institute of Health and Welfare

- Australian Suicide Prevention Advisory Council

- Australian Government Department of Health and Ageing

- Australasian Mortality Data Interest Group

- National Advisory Council on Mental Health

- Lifeline Australia

- Mindframe National Media Initiative and Hunter Institute of Mental Health

- Chief coroners and their offices, the Australasian Coroners Society and interested individual coroners

- Registry of Births Deaths and Marriages, Queensland

- Victorian Institute of Forensic Medicine

- Western Australian Ministerial Council for Suicide Prevention

- Funeral directors

- Key university researchers

- Representatives of police mental health projects in Victoria and the Northern Territory

- Regional projects between local coroners and services (eg, the Suicide Safety Network and the Coroner's Office on the Central Coast of New South Wales)

ial or NCIS cases. ${ }^{28,29}$ The proportions of coronial cases remaining open when ABS coding is finalised, with causes of death not updated with NCIS, has increased in recent years.

Moreover, the ABS progressively (from 2003), and then solely (in 2006) relied on the NCIS for coroner-certified deaths. In 2006, it abandoned manual checks. Combining this with timing-related misclassification has been crucial. "Ill-defined" deaths increased sharply in 2006 because the NCIS lacked data, especially from NSW and Qld. ${ }^{30}$ Case type (eg, inquests or those involving additional agencies such as workplaces and homicide investigators), multiple causes of death, numbers of coders, and staff training may also affect ABS outputs. ${ }^{28}$ Conceding the above trends, the ABS flagged possible suicide underreporting each year from $2005 .^{28}$

Reliable coding of suicide also requires clear, adequate definitions. Researchers of suicide nomenclature ${ }^{31}$ and the World Health Organization's ICD-10, on which the ABS relies, ${ }^{29,32}$ concur in requiring both intended self-harm and suicidal intent to delineate suicide. However, ambiguities are sometimes unavoidable; professional differences about cause assignment in possible suicide cases reflect diverse concepts, terminology and epistemology. Suicide may be probable but unconfirmed in cases where evidence of suicidal intent is unclear or the coroner has not yet decided; in fatal self-harm cases without suicidal intent; and in self-administered euthanasia. For all of these, ABS uses the "accident" default category (except for stabbings, which default to homicide). ${ }^{28}$

In March 2009, the ABS announced corrective measures for underreporting, beginning with 2007 data. ${ }^{32}$ The categories "unspecified" (R99 and X59) and "undetermined" (Y20-Y34, Y82.2), which are used when the available records lack details

\section{Aims of the National Committee for Standardised Reporting of Suicide}

- Achieving crossjurisdictional and multiparty agreement on adequate, standard and operationalised criteria and reporting formats for suicide and related data

- Identifying gaps, priorities and practical solutions within and across different domains through wide consultation

- Making recommendations to address parts of the system as well as whole systemic change

- Establishing complementary working groups that develop, pilot and implement projects

- Identifying the costs and resource implications associated with change

- Undertaking a communication strategy

about the circumstances of death or when they cannot distinguish accident and intentional self-harm, now act like holding bays for cases lacking final information at the date of coding. ${ }^{1}$ The ABS will review these cases before second and later annual releases of causes of death data registered in a particular year, revising codes as further information becomes available. In each release, some "holding-bay" cases will probably be recoded as suicide. The revised approach, using the 2007 version of ICD-10 in a manner approved by the World Health Organization Mortality Reference Group, no longer assigns cases to "accidental" causes of death codes by default. Thus, the revised approach will improve completeness and reliability, although it will reduce timeliness and simplicity. The slowness of finalisation reflects the slow completion of some coronial cases.

\section{Future directions}

A National Committee for Standardised Reporting of Suicide (NCSRS) first met in April 2009. The parties attending or consulted about this inaugural meeting are shown in Box 4, and the aims of the NCSRS are highlighted in Box 5.

The chief aim of the NCSRS is to achieve crossjurisdictional, multiparty agreement on adequate, standard and operationalised criteria and reporting formats for suicide and related data. The general domains of (i) information to coroners, (ii) coronial inquiries and reporting, and (iii) data stakeholders were identified as requiring attention. Input from coroners may improve by standardising data from primary sources (eg, police and psychological autopsies that use collective shared expertise), and training personnel. Enhanced coronial processes may include practice aids, graded determinations of suicide (eg, "possible", "probable", "beyond reasonable doubt"), and administrative leadership by chief coroners. The NCSRS will encourage coroners to find on intent where possible, recommending that problematic legislation be addressed. The NCIS and ABS may benefit from training coding staff and more detailed, consistent coding methods. Newly adopted ABS coding practices require evaluation, and may inform the 11 th revision of the International Classification of Diseases.

Other initiatives will bridge these domains. Retrospective commissioned research must revise suicide numbers. Where possible, records should identify suicides by Indigenous people, and gay, lesbian, bisexual and transgender people. Stigma must be tackled, if widespread underreporting is to cease. Joint work with coroners, forensic counselling services and those bereaved by suicide should 
identify, understand and respond to situations where suicide determinations are at variance with families' wishes. Life insurance policies with 13-month exceptions for suicide are common, and require industry reform.

Resource implications, accountability, and consultation and information processes for the NCSRS require clarification. Good potential exists for overcoming the problems, given goodwill (already apparent in the convening of the NCSRS) and appropriate resource allocation.

\section{Acknowledgements}

We are grateful to Jessica Pearse (National Coroners Information System [NCIS]) for information about NCIS processes and data analyses; Tara Pritchard (Australian Bureau of Statistics [ABS]) for information about the Australian mortality statistics system, ABS processes and coding; Helen Klieve (Australian Institute for Suicide Research and Prevention) for provision and analysis of data; Judge Neil McLean (Chief Coroner, New Zealand) for information on the coroner's role; Ryan McGlaughlin (Suicide Prevention Australia) for facilitating the National Committee for Standardised Reporting of Suicide; and Anthony Smith (Northern Sydney and Central Coast Area Health Service) for information on the Central Coast (NSW) project.

\section{Competing interests}

None identified

\section{Author details}

Diego De Leo, MD, PhD, FRANZCP, Professor of Psychiatry and Director, Australian Institute for Suicide Research and Prevention ${ }^{1}$ Michael J Dudley, MB BS, FRANZCP, Conjoint Senior Lecturer in Psychiatry, ${ }^{2}$ and Chair $^{3}$

Caroline J Aebersold, BA(Hons), Chief Executive Officer, ${ }^{4}$ and ViceChair $^{3}$

John A Mendoza, DipTeaching, BEd, GradDipHealthSci, Chair, ${ }^{5}$ and Adjunct Professor of Health Science ${ }^{6}$

Michael A Barnes, BA, LLB, LLM, Adjunct Professor, Faculty of Law, ${ }^{7}$ and State Coroner ${ }^{8}$

James E Harrison, MB BS, MPH, FAFPHM, Director, Research Centre for Injury Studies, and Associate Professor, School of Medicine

David L Ranson, BM BS, LLB FRCPA, Deputy Director, ${ }^{10}$ and Associate

Professor, Department of Forensic Medicine ${ }^{11}$

1 Griffith University, Brisbane, QLD.

2 University of New South Wales, Sydney, NSW.

3 Suicide Prevention Australia, Sydney, NSW.

4 The Song Room, Melbourne, VIC.

5 National Advisory Council on Mental Health, Canberra, ACT.

6 University of the Sunshine Coast, Sippy Downs, QLD.

7 Queensland University of Technology, Brisbane, QLD.

8 Queensland Courts, Brisbane, QLD.

9 Flinders University, Adelaide, SA.

10 Victorian Institute of Forensic Medicine, Melbourne, VIC.

11 Monash University, Melbourne, VIC.

Correspondence: m.dudley@unsw.edu.au

\section{References}

1 Harrison JE, Pointer S, Elnour AA. A review of suicide statistics in Australia. Injury research and statistics series no. 49. Canberra: Australian Institute of Health and Welfare, 2009. (AlHW Cat. No. INJCAT 121.) http:// www.aihw.gov.au/publications/inj/injcat-121-10754/ (accessed Mar 2010).

2 Australian Bureau of Statistics. Causes of death, Australia, 2007. Canberra: ABS, 2009. (ABS Cat. No. 3303.0.) http://www.abs.gov.au/Ausstats/abs@.nsf/ $\mathrm{mf} / 3303.0$ (accessed Jan 2010).

3 Corso PS, Mercy JA, Simon TR, et al. Medical costs and productivity losses due to interpersonal and self-directed violence in the United States. Am J Prev Med 2007; 32: 474-482.
4 Morrell S, Page AN, Taylor RJ. The decline in Australian young male suicide. Soc Sci Med 2007; 64: 747-754.

5 Hall WD, Mant A, Mitchell PB, et al. Association between antidepressant prescribing and suicide in Australia, 1991-2000: trend analysis. BMJ 2003; 326: 1008.

6 Goldney R. Suicide in Australia: some good news [editorial]. Med J Aust 2006; 185: 304

7 De Leo D. Suicide mortality data need revision [letter]. Med J Aust 2007; 186: 157-158.

8 Freckelton D, Ranson D. Death investigation and the coroner's inquest. Melbourne: Oxford University Press, 2006: 554-555, 632-634.

9 Australian Bureau of Statistics. Information paper. Cause of death certification Australia, 2008. Canberra: ABS, 2008: 3. (ABS Cat. No. 1205.0.55.001.) http:// www.abs.gov.au/AUSSTATS/abs@.nsf/DetailsPage/1205.0.55.0012008?OpenDocument (accessed Jan 2010).

10 O'Donnell I, Farmer R. The limitations of official suicide statistics. $\mathrm{Br} \mathrm{J}$ Psychiatry 1995; 166: 458-461.

11 Khan MM. Suicide prevention and developing countries. J Roy Soc Med 2005; 98: 459-463.

12 World Health Organization. Mental health. Prevention and special programmes. Suicide rates. Geneva. WHO, 2003. http://www.who.int/mental health/prevention/suicide/suiciderates/en/ (accessed Mar 2010).

13 De Leo D, Milner A, Wang X. Suicidal behavior in the Western Pacific region: characteristics and trends. Suicide Life Threat Behav 2009; 39: 72-81.

14 Elnour AA, Harrison J. Suicide decline in Australia: where did the cases go? Aust N Z J Public Health 2009; 33: 67-69.

15 Murray D, De Leo D. Suicidal behavior by motor vehicle collision. Traff Inj Prev 2007; 8: 244-247.

16 Australian Transport Council: National road safety action plan, 2009 and 2010. Canberra: Australian Government Department of Infrastructure, Transport, Regional Development and Local Government, 2008. http://www.atcouncil.gov.au/documents/actionplan_0910.aspx (accessed Jan 2010).

17 Eldridge D. Injury among young Australians. AlHW bulletin series no. 60. Canberra: Australian Institute of Health and Welfare, 2008: 30. (AlHW Cat. No. AUS 102.) http://www.aihw.gov.au/publications/aus/bulletin60/bulletin60.pdf (accessed Jan 2010).

18 Tatz C. Aboriginal suicide is different: a portrait of life and self-destruction. 2nd ed. Canberra: Aboriginal Studies Press, 2005: 60-63.

19 British Columbia Coroners Service. Looking for something to look forward to: a five year retrospective review of child and youth suicide in British Columbia. Prince George: Child Death Review Unit, British Columbia Coroners Service, 2008. http://www.pssg.gov.bc.ca/coroners/child-death-review/docs/cdru-suicidereportfull.pdf (accessed Jan 2010).

20 Suicide Prevention Australia. Position statement: suicide and self-harm among gay, lesbian, bisexual and transgender communities. Sydney: SPA, 2009. http://suicidepreventionaust.org/PositionStatements.aspx (accessed Jan 2010).

21 Atkinson v Morrow [2005] QCA 353.

22 Hurley v Clements \& Ors [2009] QCA 167.

$23 R v$ South London Coroner; Ex parte Thompson (1982) 126 SJ 625

24 De Leo D, Cerin E, Spathonis K, et al. Lifetime risk of suicide ideation and attempts in an Australian community: prevalence, the suicidal process, and help-seeking behaviour. J Affect Disord 2005; 86: 215-224.

25 Sands DCC. A study of suicide grief. Meaning making and the griever's relational world [PhD thesis]. Sydney: University of Technology Sydney, 2008 http://epress.lib.uts.edu.au/dspace/bitstream/2100/777/2/02whole.pdf (accessed Jan 2010).

26 Arboleda-Florez J, Sartorius N, editors. Understanding the stigma of mental illness: theory and interventions. Oxford: John Wiley and Sons, 2008.

27 Miller DN, Eckert TL. Youth suicidal behaviour: an introduction and overview. School Psych Rev 2009; 38: 153-167.

28 Australian Bureau of Statistics. Information paper: external causes of death, data quality, 2005. Canberra: ABS, 2007. (ABS Cat. No. 3317.0.55.001.) http://www.abs.gov.au/ausstats/abs@.nsf/mf/3317.0.55.001 (accessed Jan 2010).

29 Walker S, Chen L, Madden R. Deaths due to suicide: the effects of certification and coding practices in Australia. Aust N Z J Public Health 2008; 32: 126-130.

30 Australian Bureau of Statistics. Causes of death, Australia, 2006. Canberra: ABS, 2008. (ABS Cat. No. 3303.0.) http://www.abs.gov.au/AUSSTATS/ abs@.nsf/DetailsPage/3303.02006?OpenDocument (accessed Jan 2010).

31 Silverman MM, Berman AL, Rebuilding the Tower of Babel: a revised nomenclature for the study of suicide and suicidal behaviors. Part 1 and Part 2. Suicide Life Threat Behav 2007: 37: 248-277.

32 Australian Bureau of Statistics. Coding of suicide deaths, 2007. ABS technical note 1. Canberra: ABS, 2009. (ABS Cat. No. 3303.0.) http://www.abs.gov.au/ ausstats/abs@.nsf/Products/3303.0 2007 Technical+Note ABS+Coding+of+Suicide+Deaths+\%28Technical+Note\%29? OpenDocument (accessed Jan 2010).

(Received 5 Jul 2009, accepted 27 Oct 2009) 